\title{
Development and Analysis of Dynamic Time Based Pricing Scheme, RTFPP for Residential Demand Response Program
}

\author{
Mohsin Amin, Abdur Rashid and Aitazaz A. Raja*
}

Department of Electrical Engineering, COMSATS Institute of Information Technology, Abbottabad, Pakistan

\begin{tabular}{|c|c|}
\hline Abstract & Article Information \\
\hline \multirow{3}{*}{$\begin{array}{l}\text { Paper proposes fair and dynamic pricing strategy, Real Time Fair Peak Pricing } \\
\text { (RTFPP), for residential demand response program which takes into account } \\
\text { the intensity of increased load above baseline (must run load) of each user and } \\
\text { charge accordingly. Proposed methodology has the potential to increase user } \\
\text { confidence, by the induction of fairness and baseline flexibility, hence increasing } \\
\text { participation in residential demand response programs for economic operation } \\
\text { of system. An algorithm is developed to impose RTFPP scheme on given user, } \\
\text { in peak periods, for billing. To show the benefits, diverse realistic user load } \\
\text { profiles are imposed with developed algorithm in MATLAB and results are } \\
\text { evaluated and analysed. }\end{array}$} & $\begin{array}{l}\text { Article History: } \\
\text { Received : :04-07-2014 } \\
\text { Revised : 25-09-2014 } \\
\text { Accepted : } 27-09-2014 \\
\end{array}$ \\
\hline & $\begin{array}{l}\text { Keywords: } \\
\text { Load Management, } \\
\text { Residential demand response } \\
\text { Dynamic time based pricing } \\
\text { Demand side management }\end{array}$ \\
\hline & $\begin{array}{l}\text { *Corresponding Author: } \\
\text { Aitazaz A. Raja } \\
\text { E-mail: ehtazaz_ali90@hotmail.com }\end{array}$ \\
\hline
\end{tabular}

\section{INTRODUCTION}

With escalating demand of electrical energy (BP, 2012), power system is moving towards the verge of being dysfunctional. Decades old power system is inefficient and incapable of coping with large scale integration of renewable distributed generation sources for addressing this demand. Therefore future's Smart grid (SG) is supposed to align the power system with provided electronic and electrical development and be equipped with sufficient technology to meet the present and future's demands (IEEE Smart Grid, ZPRYME, 2012; Fang et al., 2012).

One of the major issues faced by today's grid is intense variation in daily load curve at different times of the day (Taylor, 1993). It is generally analysed by terms average load and peak load. Relation between them is expressed by load factor and is needed to be kept as close as possible to 1 (Mohamed, Khan, 2009).

$$
\text { Load Factor }=(\text { Average Load }) \div(\text { Maximum Load })
$$

Peak load phase usually covers few hours of the day called as peak hours but to meet this requirement utility needs to keep spinning reserve in generation capacity and also infrastructure is designed on the basis of maximum demand even if it lasts for an hour only, which is highly uneconomical. Moreover traditional electricity prices are inelastic i.e. residential customer buy electricity at flat rate even when its generation cost rises during peak hours (Lu et al., 2010). For the improvement of load profile or peak shaving different methodologies are used but as load is at user's end it is not possible to create a reliable and efficient solution without the user's participation and this aspect is well weighted in demand response (DR) programs.
DR is defined as change in load pattern by the end user in response to changing price of electricity or offered incentives. (Department of Energy, 2006). But for user's participation it is necessary to integrate interacting technology to the grid (Medina et al., 2010). SG presenting two way flow of electric power and information to create distributed and automated advanced energy delivery and management systems (Hashmi, Hanninen, 2011) can deliver significant benefits through DR programs. SG integrated advance metering Infrastructure (AMI) with its two way communication and real time response is perfect technology to implement DR in residential areas (Wang et al., 2012). Recent researches and experimentation (Freeman, Sullivan and Company, 2013) show huge opportunity for DR in residential sector.

DR programs are continuously growing in terms of peak reduction and user participation by all classes of customers. (Freeman, Sullivan and Company, 2008) Report shows 25 percent increase in potential peak reduction from 2010 to 2012 in USA from demand response programs. Specifically, potential peak reduction associated with residential customers grew by 13 percent. These figures show massive potential of demand response in electricity market and also justifies initial investment on required technology.

This paper proposes dynamic time based pricing scheme for residential demand response program which accounts for intensity of peak as well as individual customer's participation in developing that peak above its base line (must run load). 
Mohsin Amin et alo,

The overall paper consists of following sections: The section II overviews the background of DR. The section III discusses the proposed methodology. Section IV explains the experimental setup. Section V details the implementation results. Section VI concludes the paper.

\section{Demand Response Background}

DR is categorized into two major categories by Federal Energy Regulatory Commission (FERC)'s report (Federal Energy Regulatory Commission, 2012) namely time based programs and incentive based programs (Aalami et al., 2008). In price based programs price is raised in peak time to make user reduce his load. Incentive based programs (Rameez et al., 2012) provide user with some benefit/incentive for reducing demand in peak hours. In both the techniques pricing, benefit strategy plays a critical role in encouraging user for participation. Both types of programmes are further divided into sub categories on the basis of pricing and incentive strategies. Table 1 shows this categorization:

Table 1: Classification of DR Programs

\begin{tabular}{ll}
\hline Incentive-Based Programs & Time-Based Programs \\
\hline Demand Bidding and Buy Back & Critical Peak Pricing with Control \\
Direct Load Control (DLC) & Critical Peak Pricing (CPP) \\
$\begin{array}{l}\text { Emergency Demand } \\
\text { Response(EDR) }\end{array}$ & Peak Time Rebate (PTR) \\
Interruptible Load & Real Time Pricing (RTP) \\
Load as capacity resource & Time Of Use pricing (TOU) \\
Non-spinning Reserves & System Peak Response \\
Regulation service & Transmission Tariff \\
Spinning Reserve &
\end{tabular}

Pricing options that are increasingly being considered by utilities and/or regulators under time-based pricing strategies are defined below:

TOU: TOU is defined as time-varying unit usage prices for specified time periods on all weekdays for a season or year (Law et al., 2012). Time-of-use rates reflect the average cost of generating and delivering power during those time periods. TOU is a static pricing scheme in which peak period is predefined and also amount of increase in billing which varies from 1.5 to 2.5 times of off peak price. TOU distributed in tiers is easy to understand for users but it accounts for average production price throughout the period where demand may vary greatly with production cost. Moreover increase in price is not adequate to suppress user's demand in peak or reliability threatening conditions.

CPP: It is also a time varying pricing scheme but it occurs on high demand days only (Department of Energy, 2006). Pricing structure in this technique is specified and ranges from 4 to 6 times the normal price. Unlike TOU scheme high pricing intervals are not predefined in this case and are propagated to user a day before expected critical peak on the system or so.

RTP: This scheme of pricing is totally dynamic in which price may vary hourly or more often in a given day to reflect change in market conditions (Rad, Garcia, 2010). It is rather complex for common user to understand and hence threatens the willingness of participation (Alexander, 2010).

PTR: This scheme is different from previously mentioned techniques as in this technique consumer is offered
Sci. Technol. Arts Res. J., July-Sep 2014, 3(3): 156-160

rebate instead of being penalized in high demand intervals. It offers user a certain amount for each KWh not used in peak periods on high demand days.

Revenue Neutrality: In following different schemes of pricing such as TOU or CPP revenue neutral set of prices are developed that would produce the same bill of the average customer if they did not shift the load (Freeman, Sullivan and Company, 2008). To maintain this neutrality off peak prices are decreased accordingly e.g. In case of TOU rate, ratio for peak-to-off-peak prices range between 1.5 to 1 and 2.5 to 1 whereas for CPP it lies between 5 to 1 and 10 to 1 . Prices are made neutral by yearly neutrality or by seasonal neutrality. In yearly neutral schemes, prices are decreased in off peak times of the day for revenue compensation and respective pattern is followed throughout the year. In seasonal neutral schemes revenue is adjusted in a way that additional collection in high demand season will be compensated in the same season and similar approach will be followed in average to low demand seasons. In this way separate set of prices are formed on seasonal basis.

All the pricing programs discussed above charge each consumer with same increased price per unit regardless of the amount of pressure he is inserting on the system in the peak period whereas fairness demands penalty proportional to the intensity of increased demand by each user. Moreover each user should be allowed to make some baseline consumption to keep running critical load on normal rates as it cannot be reduced hence should not be penalized.

\section{MATERIALS AND METHODS}

In order to address issues creating hindrance in demand response participation this paper presents real time fair peak pricing (RTFPP) scheme. For induction of fairness factor in scheme, load for each consumer must be divided into two categories must run load and an optional load. Must run load is defined as baseline of user's load profile which is either necessity or cannot be reduced such as security system, wireless communication devices etc. Vice versa is considered as an optional load. Baseline (must run load) is determined by utility on the basis of season, region and other influencing factors. Fairness demands to impose increased price in peak period on the load above individual baseline and also considers the intensity of peak contribution by each user to charge accordingly. As the user who is not contributing in peak formation on the system i.e. operating on its baseline (must run load) should not be charged with high rates of DR program. RTFPP scheme accounts for both aspects as explained below. Figure 1 shows the basic billing methodology of scheme in peak time.

Graph depicts clearly that during peak times with increase in intensity of peak contribution by user, multiplying factor increases hence increasing the price per unit of consumption. Horizontal axis is demand normalized by baseline (must run load) of each user, taking in account the optional load only. As the extent to which load increases from base line, during peak time, square times would be increase in price. For example if user's load gets doubled he will have to pay four times the specified price for load above baseline. In this way baseline load will be charged with normal price per unit even during contingency. Point (a) on the figure shows multiplying factor i.e. 1 for off peak periods or for user keeping its load to baseline during peak time. Above 


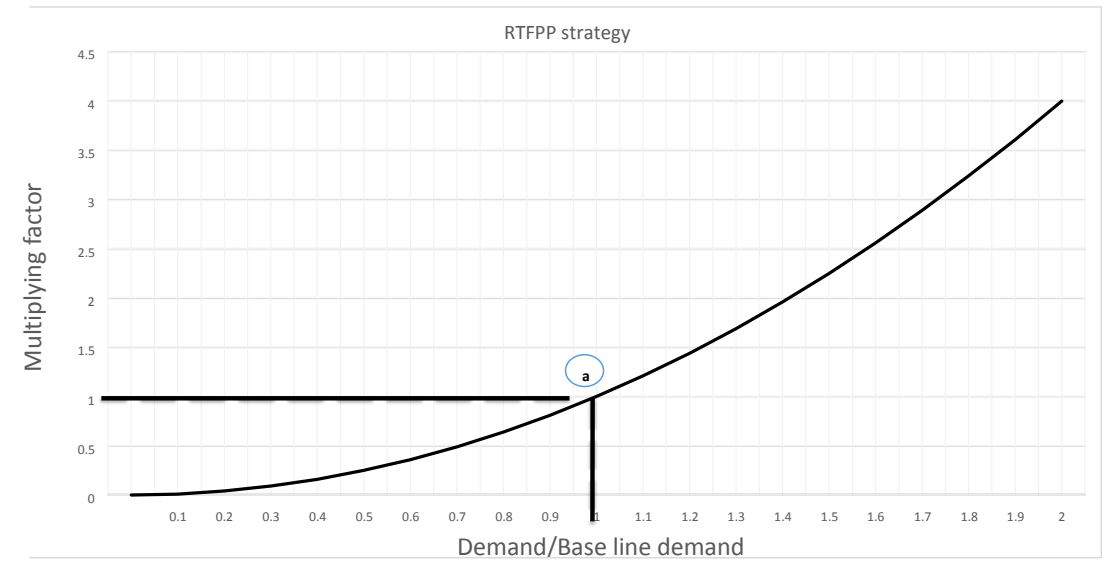

Figure 1: Billing strategy

explanation is compiled into mathematical algorithm for calculation of bill during peak period with changing intensity.

$\mathrm{n}_{p e}=$ peak period end

$\mathrm{n}_{p s}=$ peak period start $\mathrm{b}=$ base line $\mathrm{P}_{j}=$ power at specific interval $\mathrm{t}=$ tariff

$\mathrm{C}_{j}=$ Multiplying factor

$\mathrm{B}^{p k}=\sum_{n_{p s}}^{n_{p e}}\left[P_{j}-b\right] C_{j} \times t+[b \times t]$

Multiplying factor at any interval

$\mathrm{C}=[P \div b]^{2}$

Bill is calculated for peak period in specified time intervals e.g. after every 15 minutes for average values, depending upon the technology available for monitoring and data handling. For advanced monitoring and handling, system is considered to be integrated with Advanced Metering Infrastructure (AMI). Without availability of such technology, benefits of RTFPP could not be attained.

Figure 2 shows centrally coordinated model required for the implementation of DR in smart cities.

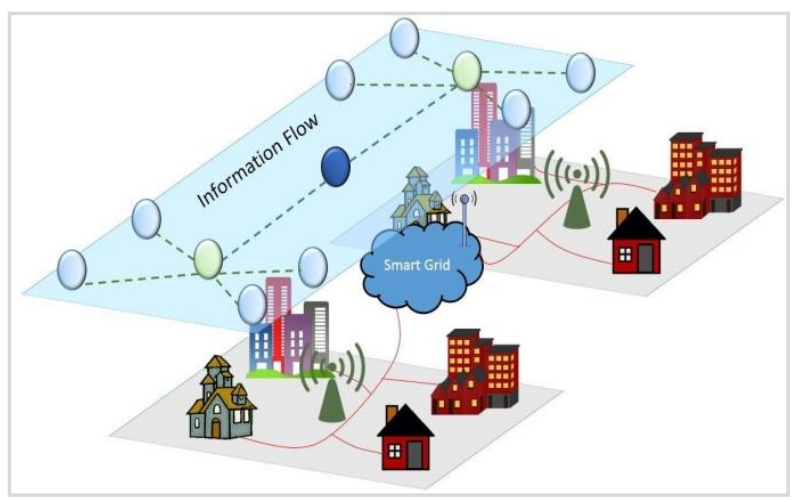

Figure 2: Basic implementation infrastructure

Initially argument can be made against RTFPP for its complexity as price should be understandable to be effective. But with the efficient method of propagation, it can be brought easily under the user's understanding level.

\section{Experimental Setup}

Simulation is created in order to quantify the performance of proposed pricing scheme under diverse conditions. Load profiles of 3 individual residential customers with different trend of demand are taken as program participants. RTFPP scheme is imposed for analysis and also compared to conventional flat rate and static TOU pricing rate. In static TOU strategy peak time is defined to be interval from $12 \mathrm{pm}$ to $6 \mathrm{pm}$. For RTFPP as strategy determines peak period dynamically hence it is determined by central monitoring authority of utility on the basis of accumulated LP. RTFPP baseline is taken to be $0.5 \mathrm{KW}$ for simulation purpose.

\section{RESULTS AND DISCUSSION}

All expected reductions made in given load profiles are on the basis of conclusions by extensive pilot projects report (Freeman, Sullivan and Company, 2008) states that during peak period user reduces its load by 11 to 25 percent in response to 4 to 6 times increase in price from regular rate.

Figure 3 shows hourly load profile (LP) of a user with high demand. During forecasted peak period user demand increased almost 200 percent of its baseline. Expected peak reduction in individual load profile in response to DR program is shown with dashed line.

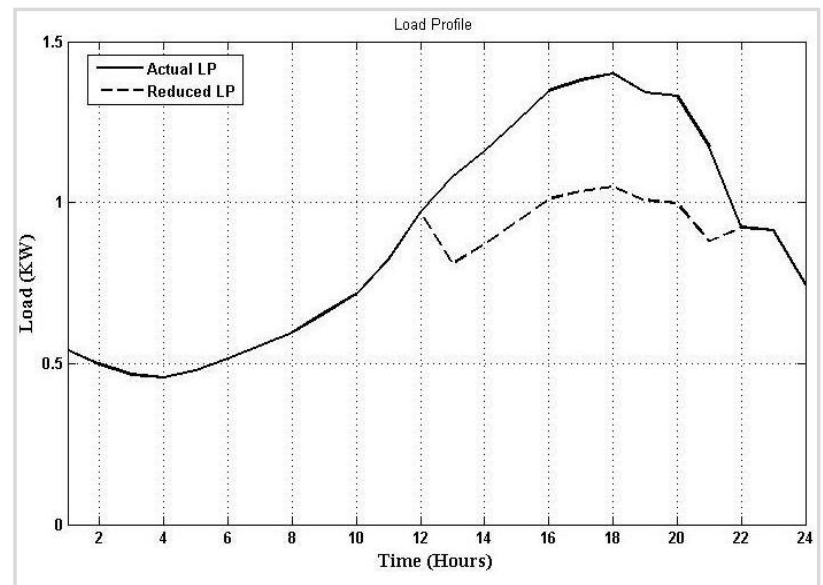

Figure 3: Consumer 1's load profile, with high peak contribution

Figure 4 shows Hourly billing pattern of consumer 1 . As evident, in flat rate scheme price per unit remained constant. Whereas static TOU pricing scheme shows increased rate in defined interval and RTFPP scheme shows drastic increase with dynamic determination of peak. 
Mohsin Amin et al.,

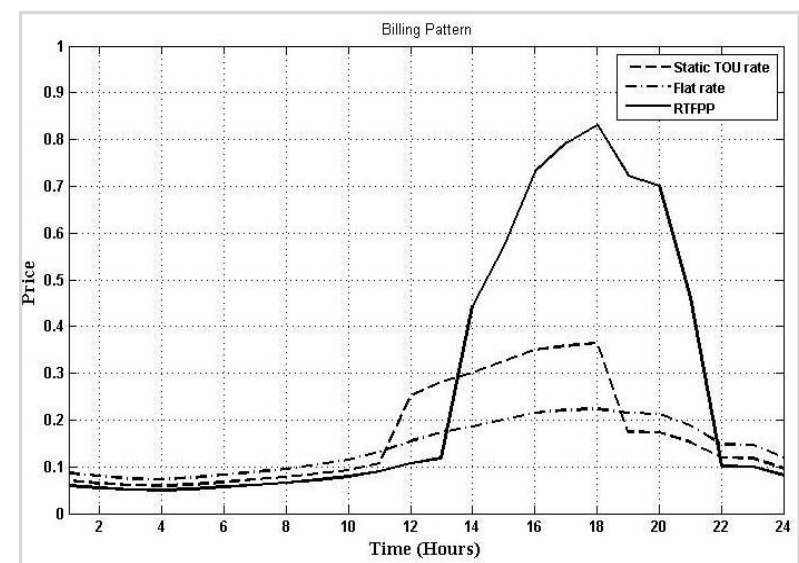

Figure 4: Consumer 1's hourly billing pattern, Price per unit $\mathrm{x} \mathrm{kWh}$ used

Figure 5 shows price per KWh in intervals which clearly depicts the methodologies of compared pricing schemes. It also shows the benefit provided to program participants in off peak regions by DR imposing utilities. Rate sets are carefully determined by utilities to make scheme revenue neutral. In flat rate scheme price per unit remained constant for whole day even when utilities were generating electricity at higher costs during peak periods. Static TOU rate shows double rate in defined interval regardless of the intensity of peak as well as its contribution by each user. Whereas RTFPP scheme shows dynamic peak period demarcation as well as changing rates with changing peak contribution of user.

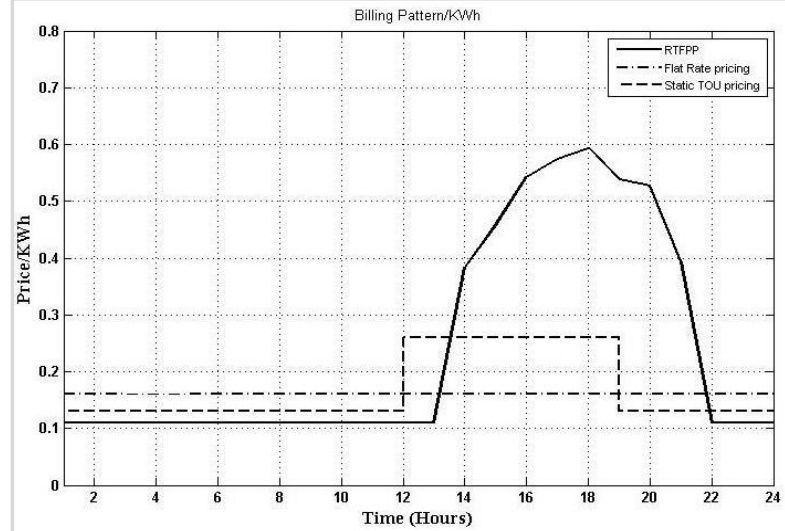

Figure 5: Consumer 1's hourly billing pattern, Price per unit

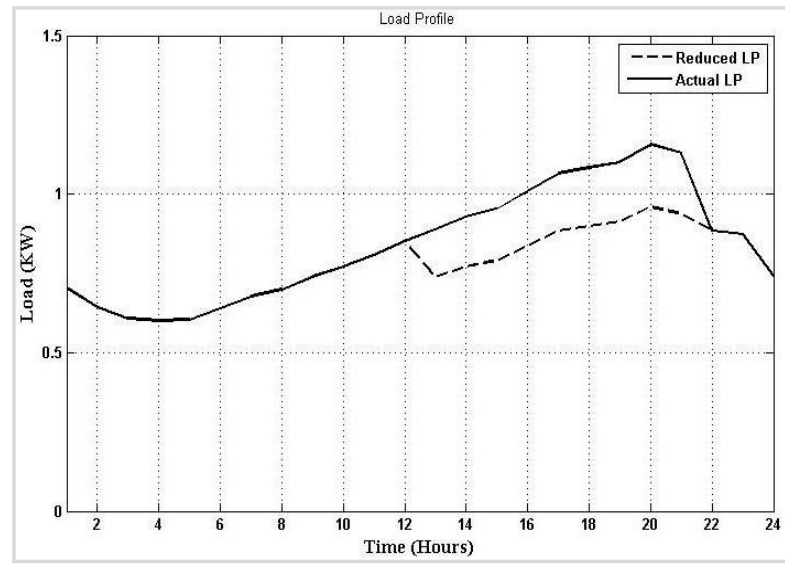

Figure 6: Consumer 2's load profile, with medium peak contribution
Sci. Technol. Arts Res. J., July-Sep 2014, 3(3): 156-160

Figure 7 and 8 show billing pattern of Consumer 2 with medium demand during peak period, as demand is lower behaviour of flat and static TOU schemes remained same as in earlier case but RTFPP responded dynamically to this level of consumption and dealt fairly with respective user. Another drawback of static TOU pricing is also evident that it accounts for defined interval even if peak shifts in varying circumstances.

Consumer 3's energy requirement in figure 9 is quite low and contributes minutely in system's peak therefore should be minutely penalized in terms of per unit pricing.

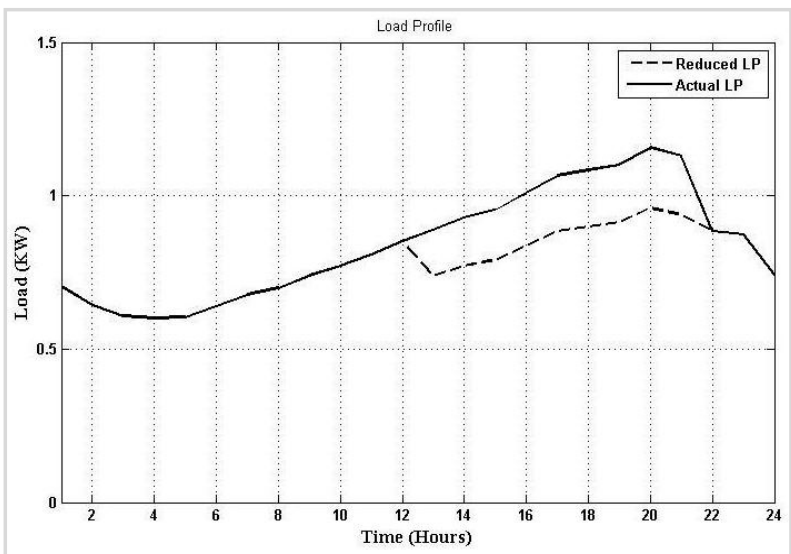

Figure 7: Consumer 2's hourly billing pattern, Price per unit $\mathrm{x}$ kWh used

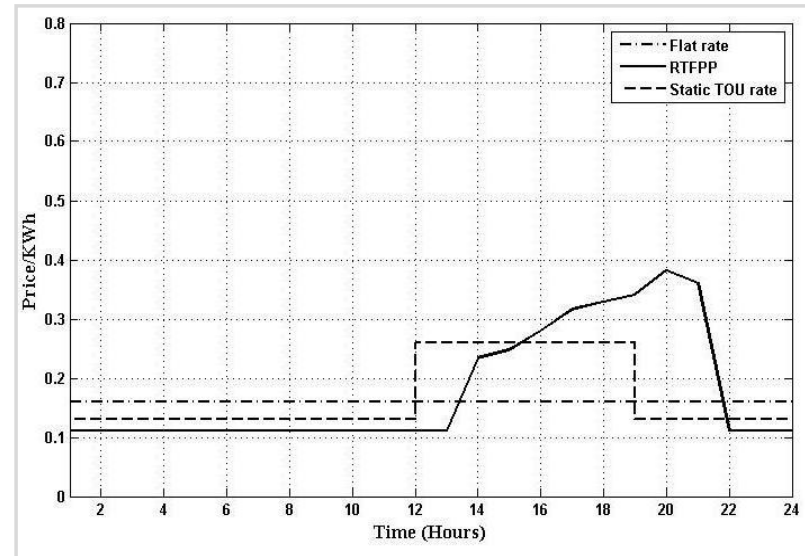

Figure 8: Consumer 2's hourly billing pattern, Price per unit

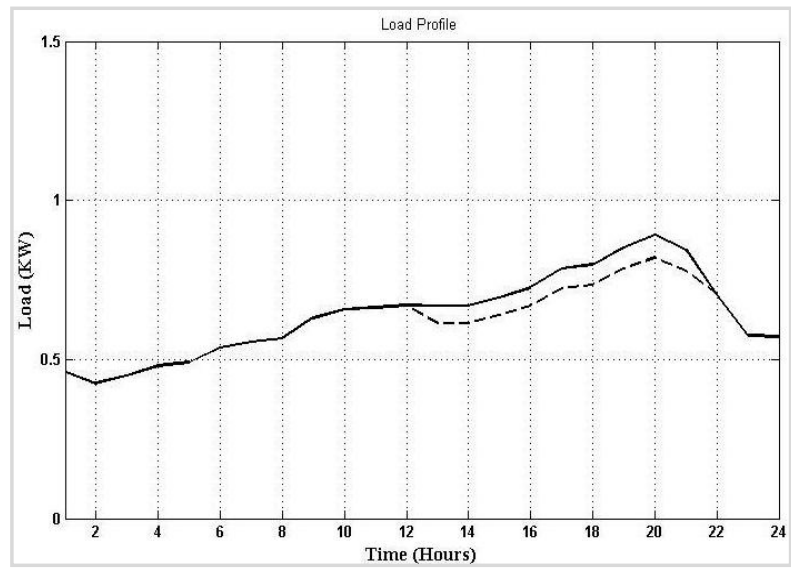

Figure 9: Consumer 3's load profile, with low peak contribution 
Mohsin Amin et al.,

Figure 10 and 11 shows billing pattern of user with low demand, price per unit of flat and static TOU pricing show similar behaviour. In contrast RTFPP encourages user behaviour in peak period hence rate gets lower.

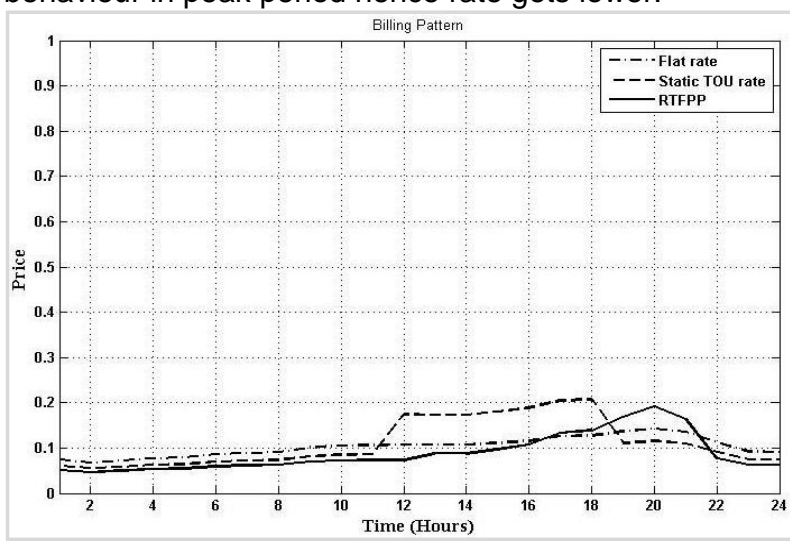

Figure 10: Consumer 3's hourly billing pattern, Price per unit $\mathrm{x} \mathrm{kWh}$ used

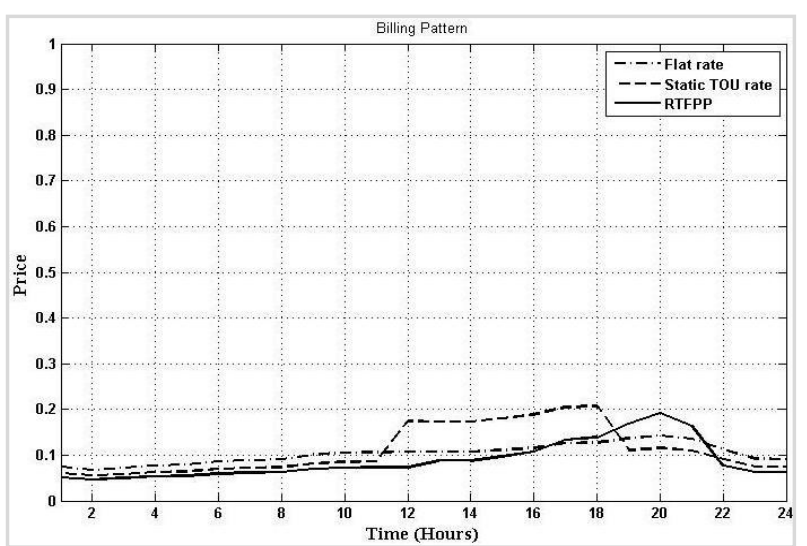

Figure 11: Consumer 3's hourly billing pattern, Price per unit

\section{CONCLUSIONS}

In this paper the, novel pricing scheme for residential DR program, RTFPP is legitimized in terms of peak reduction and economic operation of system. Induction of fairness by baseline factor is anticipated to increase user participation considerably hence extracting and utilizing the complete benefit depiction of parabolic pricing. MATLAB simulation is created and respective strategy is imposed on diverse data which showed eminence of scheme in reducing high demand peaks. Also comparison of RTFPP with flat rate and static TOU schemes showed obvious improvement in performance.

The infrastructure required for implementing demand side load management is increasingly and swiftly being deployed hence eliminating the long standing hurdle. Therefore innovative and encouraging DR programs are needed for their penetration in residential sector.

\section{REFERENCES}

Aalami, H.A., Yousefi, G.R. and Moghaddam, M.P. (2008). Demand Response Model Considering EDRP and TOU Program. IEEE/PES Transmission and Distribution Conference and Exposition pp. 1-6.

Alexander B.R. (2010). Dynamic Pricing Not So Fast A Residential Consumer Perspective, The Electricity Journal 23(6): 39-49.
Sci. Technol. Arts Res. J., July-Sep 2014, 3(3): 156-160

BP's (2012). Statistical Review of World Energy.

Taylor, C.W. (1993). Power system voltage stability, McGraw Hill.

Demand Response Program Types. [ONLINE] Available at: http/www.demandresponsedirectory.com/programtypes. html. [Accessed 2 January 2014 Department of Energy, (2006). Benefits of Demand Response in Electricity Markets and Recommendations for Achieving Them, United States of America.

Department of Energy. (2006). A report to the US Congress pursuant to section 1252 of the energy policy act of 2005, United States of America.

Fang, X., Misra, S., Xue, G., Yang, D. (2012). Smart Grid â The New and Improved Power Grid: A Survey. IEEE Communications Surveys and Tutorials 14(4): 944-980.

Federal Energy Regulatory Commission (2012). Assessment of Demand Response and Advanced Metering.

Freeman, Sullivan and Company (2008). Benefit-Cost Analysis for Advanced Metering and Time Based Pricing, Freeman, Sullivan and Company.

Freeman, Sullivan and Company (2013). Relevant Demand Response Experience and Applications in North America.

Hashmi, M., Hanninen, S. and Maki, K. (2011). Survey of smart grid concepts, architectures, and technological demonstrations worldwide, IEEE PES Conference on Innovative Smart Grid Technologies (ISGT Latin America), pp. 1-7.

IEEE Smart Grid, ZPRYME. (2012). IEEE smart grid power systems of future: The case for Energy storage, Distributed generation, and Micro-grids. Smart Grid Insights.

Law, Y.W., Alpcan, T., Lee, V.C.S., Lo, A., Marusic, S. and Palaniswami, M. (2012). Demand response architectures and load management algorithms for energy efficient power grids a survey, Seventh International Conference on Knowledge, Information and Creativity Support System, pp. 134-141.

Lu, E., Brooks, A., Reicher, D., Spirakis, C. and Weihl B. (2010). Demand dispatch. IEEE Power and Energy Magazine 8(3): 20-29.

Medina, J., Muller, N. and Roytelman, I. (2010). Demand Response and Distribution Grid Operations: Opportunities and Challenges. IEEE Transactions on Smart Grid 1(2): 193-198.

Mohamed, A. and Khan, T.K. (2009). A review of electrical energy management techniques: supply and consumer side industries, Journal of Energy in Southern Africa 20(3): 14-21.

Rad, A.H.M. and Garcia, A.L. (2010). Optimal residential load control with price prediction in real-time electricity pricing environments. IEEE Transactions on Smart Grid 1(2): 120-133.

Rameez, M., Ali, M., Zaidi, Z.A., Zia, Q., Zakaria, M. and Ahsan, S.M. (2012). Intelligent Load Management Scheme for a Residential Community in Smart Grids Network Using FEDRP. WSEAS Transactions on Power Systems 7(3): 104-113.

Taylor, C.W. (1993). Power system voltage stability, McGraw Hill.

Wang L., Kusiak A. and Dounis A. (2012). Guest Editorial Special Section on Intelligent Buildings and Home Energy Management in a Smart Grid Environment. IEEE Transactions on Smart Grid 3(4): 119-2120. 